\title{
CRESCIMENTO DE Spirulina sp. LEB 18 UTILIZANDO DIFERENTES CONCENTRAÇÕES DE NITRATO DE SÓDIO
}

\author{
A. L. CORRÊA ${ }^{1}$, M. M. FONTOURA ${ }^{1}$, M. C. VEIGA $^{1}$ e L. O. SANTOS $^{1}$ \\ ${ }^{1}$ Universidade Federal do Rio Grande, Escola de Química e Alimentos \\ E-mail para contato: santoslucielen@gmail.com
}

\begin{abstract}
RESUMO - As microalgas possuem alta taxa fotossintética e são conhecidas por apresentarem elevada produção de biomassa, podendo duplicar sua biomassa em apenas um dia. A biomassa microalgal possui composição bioquímica diversificada e devido a isso vem sendo bastante utilizada como fonte de alimento e de energia limpa. A cianobactéria Spirulina se destaca das demais microalgas devido sua composição, que contém ácidos graxos poli-insaturados, vitaminas e elevado teor proteico (60-70\%), por isso é muito utilizada em suplementos alimentares. Com o intuito de obter melhores resultados no crescimento celular e na composição proximal da biomassa, podem ser realizadas modificações nas concentrações de nutrientes do meio de cultivo. Para este estudo foi utilizada Spirulina sp. LEB 18 em meio Zarrouk contendo diferentes concentrações de nitrato de sódio $\left(1,875 \mathrm{~g} \mathrm{~L}^{-1}\right.$ e $\left.2,5 \mathrm{~g} \mathrm{~L}^{-1}\right)$. Os ensaios foram realizados em fotobiorreatores tubulares de $2 \mathrm{~L}$, com volume útil de $1,8 \mathrm{~L}$ durante $16 \mathrm{~d}$ a $35{ }^{\circ} \mathrm{C}$. Diariamente foram realizadas análises para determinação da concentração celular e pH. Para os ensaios contendo a concentração de $1,875 \mathrm{~g} \mathrm{~L}^{-1}$ de nitrato de sódio, obteve-se concentração de biomassa máxima $\left(\mathrm{X}_{\operatorname{máx}}\right)$ de $1,12 \pm 0,07 \mathrm{~g} \mathrm{~L}^{-1}$ e $1,01 \pm$ $0,02 \mathrm{~g} \mathrm{~L}^{-1}$, utilizando a concentração $2,5 \mathrm{~g} \mathrm{~L}^{-1}$. O pH dos cultivos ficou na faixa de crescimento da cianobactéria Spirulina de 9,6 a 10,5.
\end{abstract}

\section{INTRODUÇÃO}

As microalgas são micro-organismos com capacidade fotossintética, o que permite converter a energia solar em biomassa. Sua biomassa é muito utilizada na formulação de diversos produtos, devido a sua composição bioquímica diversificada, que se destacam carboidratos, proteínas e lipídeos. A cianobactéria Spirulina é uma microalga filamentosa, multicelular com coloração verde azulada, por apresentar elevada concentração de proteínas e baixo teor de gordura, possui grande potencial para a produção de alimentos funcionais (KARAM; SOCCOL, 2007).

A exposição das microalgas a situações de estresse pode aumentar a produção de biomassa, além de induzir a produção de biomoléculas de interesse. Essas situações são causadas através da manipulação das condições de cultivo, como: temperatura, iluminação, $\mathrm{pH}$ e concentrações de nutrientes no meio de cultivo (LOURENÇO, 2006). Sendo assim o objetivo do trabalho foi estudar a modificação da concentração de nitrato de sódio $\left(1,875 \mathrm{gL}^{-1}\right.$ e $2,5 \mathrm{~g} \mathrm{~L}^{-1}$ ) no meio de cultivo utilizando a temperatura de $35^{\circ} \mathrm{C}$ e avaliar sua influência no crescimento da microalga Spirulina sp. LEB 18. 


\section{MATERIAL E MÉTODOS}

\subsection{Micro-organismo e condições de cultivo}

No presente trabalho utilizou-se a cianobactéria Spirulina $s p$. LEB 18, isolada da Lagoa Mangueira localizada no município de Santa Vitória do Palmar - RS (MORAIS et al., 2008) esta foi mantida em meio Zarrouk (ZARROUK, 1966) padrão utilizando $2,5 \mathrm{~g} \mathrm{~L}^{-1} \mathrm{de}$ nitrato de sódio $\left(\mathrm{NaNO}_{3}\right)$, o mesmo meio foi utilizado para estudar a redução da fonte de nitrogênio, utilizando a concentração de $1,875 \mathrm{~g} \mathrm{~L}^{-1}$ de $\mathrm{NaNO}_{3}$.

Os cultivos foram realizados em fotobiorreatores verticais de $2 \mathrm{~L}$, com volume útil de $1,8 \mathrm{~L}$ e concentração inicial de $0,2 \mathrm{~g} \mathrm{~L}^{-1}$. Os cultivos foram mantidos em estufa termostatizada a $35^{\circ} \mathrm{C}$, iluminância de $30 \mu \mathrm{mol} \mathrm{m} \mathrm{s}^{-2}$ e fotoperíodo de $12 \mathrm{~h}$ claro/escuro. Para a aeração dos cultivos foi utilizada a vazão de $0,3 \mathrm{vvm}$ (volume de ar volume de meio ${ }^{-1} \mathrm{~min}^{-1}$ ).

A evaporação da água durante os cultivos foi compensada diariamente com a manutenção do volume das culturas com água destilada estéril. Foram realizados dois cultivos em triplicata. Diariamente foi retirado $5 \mathrm{~mL}$ de amostra para fazer a avaliação do $\mathrm{pH}$ e concentração celular.

\subsection{Determinações da concentração celular e pH}

O crescimento celular foi determinado através da medida de densidade ótica dos cultivos em espectrofotômetro, a $670 \mathrm{~nm}$, utilizando curva padrão que relaciona a densidade ótica e a massa seca de biomassa. $\mathrm{O}$ pH dos cultivos foi avaliado através de leitura direta em pHmetro digital. $\mathrm{O}$ crescimento celular e o $\mathrm{pH}$ foram acompanhados diariamente.

\subsection{Parâmetros cinéticos}

Os parâmetros cinéticos avaliados foram: a produtividade máxima ( $\left.\mathrm{P}_{\text {máx }}\right)$ (Equação 1), velocidade específica máxima de crescimento $\left(\mu_{\text {máx }}\right)$ (Equação 2$)$, concentração de biomassa máxima $\left(\mathrm{X}_{\text {máx }}\right)$ e tempo de geração $\left(\mathrm{t}_{\mathrm{g}}\right)$ (Equação 3$)$.

$$
\begin{aligned}
& P_{\max }=\frac{\left(X-X_{0}\right)}{\left(t-t_{0}\right)} \\
& \mu_{\text {máx }}=\frac{1}{x} \cdot \frac{d x}{d t} \\
& t_{g}=\frac{\ln (2)}{\mu_{\text {max }}}
\end{aligned}
$$




\subsection{Avaliação dos parâmetros cinéticos}

As respostas obtidas nos ensaios foram avaliadas por análise de variância (ANOVA) e por teste de Tukey para comparação entre médias, com intervalo de significância de $95 \%$ de confiança.

\section{RESULTADOS E DISCUSSÃO}

A Figura 1 apresenta a concentração de biomassa de Spirulina sp. LEB 18 ao longo do tempo de cultivo. É possível observar que houve aumento no crescimento celular a partir do $3^{\circ} \mathrm{d}$ de cultivo, isto pode ter ocorrido devido à microalga estar se adaptando as condições de cultivo. A maior concentração de biomassa encontrada utilizando $1,875 \mathrm{~g} \mathrm{~L}^{-1}$ de $\mathrm{NaNO}_{3}$ foi no $15^{\circ} \mathrm{d}$, enquanto utilizando a concentração de $2,5 \mathrm{~g} \mathrm{~L}^{-1}$, foi no $16^{\circ} \mathrm{d}$.

Figura 1. Concentração de biomassa de Spirulina sp. LEB 18 utilizando diferentes concentrações de $\mathrm{NaNO}_{3}, 1,875 \mathrm{~g} \mathrm{~L}^{-1}$ (x) e 2,5 $\mathrm{g} \mathrm{L}^{-1}$ (o).

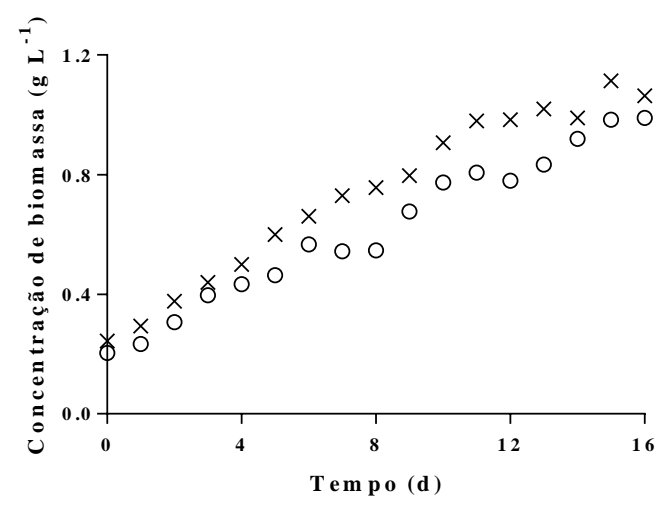

Como pode ser observado na Tabela 1, não houve diferença significativa no crescimento de Spirulina sp. LEB 18 utilizando as diferentes concentrações de $\mathrm{NaNO}_{3}$. A utilização das concentrações de $1,875 \mathrm{~g} \mathrm{~L}^{-1}$ e $2,5 \mathrm{~g} \mathrm{~L}^{-1}$ resultaram em produtividades de $0,06 \pm$ $0,01 \mathrm{~g} \mathrm{~L}^{-1} \mathrm{~d}^{-1}$ e $0,05 \pm 0,00 \mathrm{~g} \mathrm{~L}^{-1} \mathrm{~d}^{-1}$, respectivamente.

Os resultados encontrados foram superiores aos reportados por Colla et al (2007), que utilizaram variação da concentração de $\mathrm{NaNO}_{3}$ no intervalo de $0,625 \mathrm{~g} \mathrm{~L}^{-1}$ a $2,5 \mathrm{~g} \mathrm{~L}^{-1}$, e encontraram valores próximos a $0,02 \pm 0,00 \mathrm{~g} \mathrm{~L}^{-1} \mathrm{~d}^{-1}$, utilizando a mesma temperatura. $\mathrm{O}$ presente estudo demonstra que a quantidade desse nutriente pode ser reduzida no meio de Zarrouk, sem perdas e com diminuição no custo de produção. Entretanto, será possível verificar se houve alteração na composição proximal após a caracterização da biomassa, e a partir desta análise será definida aplicação para a biomassa. 
Tabela 1. Concentração de biomassa máxima $\left(\mathrm{X}_{\text {máx }}\right)$, produtividade máxima $\left(\mathrm{P}_{\text {máx }}\right)$, velocidade específica máxima de crescimento $\left(\mu_{\text {máx }}\right)$ e tempo de geração $\left(t_{\mathrm{g}}\right)$ obtidos nos cultivos de Spirulina sp. LEB 18 utilizando $1,875 \mathrm{~g} \mathrm{~L}^{-1}$ e 2,5 $\mathrm{g} \mathrm{L}^{-1}$ de $\mathrm{NaNO}_{3}$.

\begin{tabular}{|c|c|c|}
\hline & $\begin{array}{c}\text { Ensaio com } \\
1,875 \mathrm{~g} \mathrm{~L}^{-1} \mathrm{NaNO}_{3}\end{array}$ & $\begin{array}{c}\text { Ensaio com } \\
2,5 \mathrm{~g} \mathrm{~L}^{-1} \mathrm{NaNO}_{3}\end{array}$ \\
\hline$X_{\text {máx }}\left(\mathrm{g} \mathrm{L}^{-1}\right)$ & $1,12 \pm 0,07^{\mathrm{a}}$ & $1,01 \pm 0,02^{\mathrm{a}}$ \\
\hline$P_{\text {máx }}\left(g^{-1} d^{-1}\right)$ & $0,06 \pm 0,01^{\mathrm{a}}$ & $0,05 \pm 0,00^{\mathrm{a}}$ \\
\hline$\mu_{\text {máx }}\left(d^{-1}\right)$ & $0,18 \pm 0,01^{\mathrm{a}}$ & $0,19 \pm 0,02^{\mathrm{a}}$ \\
\hline $\mathbf{t}_{\mathrm{g}}(\mathrm{d})$ & $3,91 \pm 0,15^{\mathrm{a}}$ & $3,62 \pm 0,32^{\mathrm{a}}$ \\
\hline
\end{tabular}

Letras minúsculas iguais representam que não há diferença significativa entre colunas a $95 \%$ de confiança $(\mathrm{p}<0,05)$

A Figura 2 apresenta o pH dos cultivos de Spirulina sp. LEB 18 ao longo do tempo de cultivo, pode-se perceber que a faixa de $\mathrm{pH}$ variou bastante em ambos cultivos. $\mathrm{O} \mathrm{pH}$ do cultivo deve ser mantido alcalino, pois esta microalga cresce de forma natural em ambientes com elevada salinidade e alcalinidade (VONSHAK, 1997). De acordo com Belay (1997) fora do intervalo entre 10 e 11, os cultivos podem estar suscetíveis à contaminação. Enquanto que Shiraiwa et al., (1993) sugeriu que o aumento do $\mathrm{pH}$ pode ocorrer em função do metabolismo autotrófico, onde o íon bicarbonato do meio se desidrata formando $\mathrm{CO}_{2}$, fazendo com que ocorra a fotossíntese.

Figura 2. Faixa de $\mathrm{pH}$ dos cultivos de Spirulina sp. LEB 18 utilizando diferentes concentrações de $\mathrm{NaNO}_{3}, 1,875 \mathrm{~g} \mathrm{~L}^{-1}(\mathrm{x})$ e $2,5 \mathrm{~g} \mathrm{~L}^{-1}$ (०).

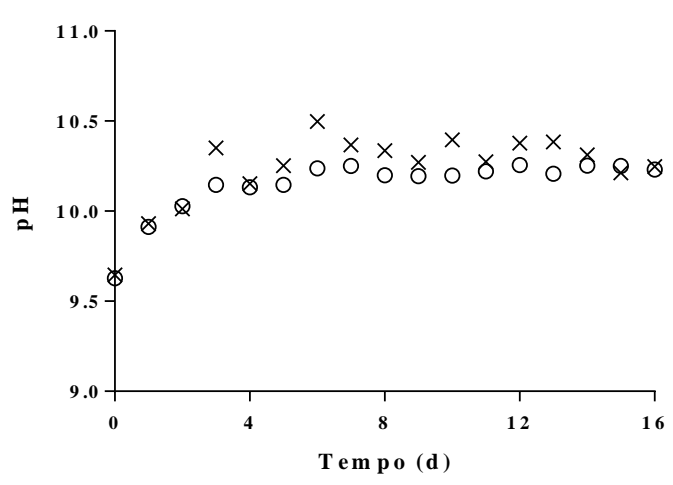

\section{CONCLUSÃO}

A utilização de diferentes concentrações de nitrato de sódio $\left(1,875 \mathrm{~g} \mathrm{~L}^{-1}\right.$ e $\left.2,5 \mathrm{~g} \mathrm{~L}^{-1}\right)$ no meio de cultivo utilizando a temperatura de $35{ }^{\circ} \mathrm{C}$, não diferiu significativamente no crescimento da microalga Spirulina sp. LEB 18, porém após realizar a caracterização da biomassa, será possível verificar se ocorreram modificações na composição da biomassa microalgal. 


\section{REFERÊNCIAS}

BELAY, A. Mass culture of Spirulina outdoors: the Earthrise farms experience. In: VONSHAK, A. Spirulina platensis (Arthrospira) physiology, cell-biology and biotechnology. London: Taylor \& Francis, 233 p. 1997.

COLLA, L. M.; REINEHR, C. O.; REICHERT, C.; COSTA, J. A. V. Production of biomass and nutraceutical compounds by Spirulina platensis under different temperature and nitrogen regimes. Bioresource Technology, v. 98, n. 7, p. Spirulina 1489-1493, 2007.

KARAM, L. M.; SOCCOL, C. R. Efeito da temperatura e pH no cultivo de Spirulina major. Arq. Ciênc. Vet. Zool. Unipar, v. 10, n. 1, p. 5-7, 2007

LOURENÇO, S. O. Cultivo de Microalgas Marinhas: Princípios e Aplicações. São Carlos: RiMa, 2006.

MORAIS, M. G.; REICHERT, C. C.; DALCANTON, F.; DURANTE, A. J.; MARINS, L. F.; COSTA, J. A. V. Isolation and characterization of a new Arthrospira Strain. Zeitschrift fur Naturforschung, v. 32, p. 1879-1880, 2008.

SHIRAIWA, Y.; GOYAL, A.; TOLBERT, N. E. Alkalization of the medium by unicellular green algae during uptake of dissolved inorganic carbon. Plant Cell Physiology, v. 34, n. 5, p. 649-657, 1993.

VONSHAK, A. Spirulina platensis (Arthrospira): physiology, cell-biology and biotechnology. London: Taylor \& Francis, 1997.

ZARROUK, C., 1966. Contribution à l'étude d'une cyanophycée. Influence de divers facteurs physiques et chimiques sur la croissance et la photosynthèse de Spirulina maxima. Ph.D Thesis, Université de Paris. 